\title{
III. On the great importance of deviations from the mean state of the atmosphere for the science of meteorology
}

\section{Dr. Buys Ballot}

To cite this article: Dr. Buys Ballot (1850) III. On the great importance of deviations from the mean state of the atmosphere for the science of meteorology, Philosophical Magazine Series 3, 37:247, 42-49, DOI: $10.1080 / 14786445008646549$

To link to this article: http://dx.doi.org/10.1080/14786445008646549

曲 Published online: 30 Apr 2009.

Submit your article to this journal $\pi$

ЏII Article views: 2

Q View related articles $₫$ 
I do not feel myself competent to express a decided opinion upon this "vexed question;" but regarding the lake theory as the true one, I think it now only remains to be determined whether the barriers at the mouths of the glens consisted of ice or of earthy materials. Perhaps we know nearly as much regarding the latter as we ever can know; but the valley of the Spean has never been carefully exumined, with reference to the former passage of glaciers through it, by one fully competent to the task. Till this has been done, geologists are not in a position to decide between the rival theories.

1II. On the great importance of Deviations from the mean state of the Atmosphere for the Science of Meteorology. By Dr. Buys Ballot*.

THERE are some points in meteorology which certainly 1 are no longer disputed, but which nevertheless are not always sufficiently present to the minds of meteorologists, nor so publicly pronounced and admitted as to compel them to action, and serve as a torch to illumine the path leading to the penetralia of science. Though these facts may appear simple, particularly in England, where they have been treated upon, still even there it cannot be considered superfuous to view them in another light, and to introduce them in connexion with a Dutch prize question, which, in my opinion, is the most important meteorological question that can be brought forward, and which fully characterizes the new meteorological period developed by Dove.

On the other hand, England has such boundless merits as to meteorological observations, and has such great facilities, in consequence of her extensive influence and wide-spread observatories, for the application of those facts in all parts of the earth, that she has a right to receive information, through her own periodicals, of what is taking place on the continent. I therefore decided (on being solicited by the Society of Physics of Berlin to send in annually a report of, and opinions on, what might occur in meteorology) to adopt also for insertion in an English periodical, by modifying some points of less interest, a paper drawn up for the Jourual of the Society, Die Fortschritte der Physik. The truths to which I allude were particularly remarked by me in 1846, when I wrote my work Les Changements Périodiques de Température dépendants de la nature du Soleil et de la Lune déduits d'observations Neerlandaises de 1729-1846, in which those parti-

* Communicated by the Astronomer Royal. 
culars are to be found, chapter vii. p. 104 et seq. But let us proceed to those propositions.

I. The average temperature which prevails at any certain place is not that which is generated there by the action of the sun, \&c., and which would depend simply on the latitude and the elevation of the ground, but is remarkably changed by the influences of other regions, particularly by the action of the winds.

II. That average temperature, such as it is obtained anywhere from observations during a series of years, for the different months or days of the year, will by no means always prevail at those places for the determined month or day of each single year. On the contrary, observations give generally great variations; and it is precisely the magnitude of these variations which it is of the utmost importance to learn.

III. What we asserted regarding the temperature in proposition II. applies equally to all meteorological indications; it is of great importance to become acquainted with those variations of the barometer, and of the force and direction of the wind.

IV. The most efficient means for prognosticating the weather are, the employment of the electric telegraphs and of self-registering instruments, because they facilitate and make possible a tabular union of the variations mentioned in II. and III.

In the following remarks these propositions are more fully developed.

Art. I. No one can call in question our first proposition, we shall not therefore demonstrate it; we will only observe, that it is the winds that modify this temperature; we will endeavour to ascertain how much is to be ascribed to each wind.

Let $\Theta$ represent for longer, $\theta$ for shorter spaces of time, the mean theoretical temperature of a place, and let MT and $m t$ represent the mean temperature deduced from long series of observations, OT and ot the abserved mean temperature for that longer or shorter space of time at the same place in a given year; then we need only annex some distinctive symbols to these three signs in order to show of which space of time we are speaking. Therefore, when we speak of years or seasons, we shall annex the first letters of the words year, $y$; winter, w; spring, sp.; summer, su.; autumn, $\alpha$, at the foot of the great letters; and when we speak of months, we shall annex the first letter of the name of the month after the small letters. Thus $\Theta y$ will signify the mean temperature of the year, $\theta f$ the mean temperature of February, which ought to prevail at a certain place, if that place did not receive warmth from and 
impart warmth to the surrounding parts : it will readily be perceived that these values must ever be the same for each place situated in the same latitude and elevation above the sea. On what does it depend that MTy and mtf are not found alike in all the places in the same parallel, but always different in every different place; lower in this, higher in that, than $\Theta y$ and $\theta f$ ? If there was a parallel circle which extended wholly over a continent, or if we passed regularly over a parallel circle in a ship, and if we determined the MTy in $n$ different selected places, then would $\frac{\Sigma M T y}{n}$ be nearly expressed by $\Theta y$; the value so obtained would, however, be somewhat greater than $\Theta y$, because there is more air drawing towards the north than towards the south over a whole parallel circle, that southern air at the same time being warmer; and also because, near the equator, the latent heat which is employed in the vaporizing of water is greater than that which is freed by rain; and, on the contrary, in higher latitudes there is more freed than expended on the formation of vapour. This is also a cause why on the land $\Theta y$ must be something less than at sea. If we would nicely calculate this influence, we ought equally to distinguish between rain that is formed in different altitudes. Properly we ought to infer theoretically $\Theta y$, and equally so $\theta f$, from the warmth which emanates from the sun to us every day; from the warmth which every day and night issues from beneath the surface of earth; and from the warmth that is produced by animals, consumed by plants, lost by radiation, given by condensation of vapour. 'The difference between $\Theta y$ so obtained, and MTy, (MTy- $\Theta y)$, at a certain place, is to be ascribed to the influence of the wind during the year; similarly, $m t f-\theta f$ is the influence of the wind which prevails in February at that place. How far we are as yet from such a determination may be seen, for example, from the meteorology of the late illustrious Daniell. But even if it could be obtained, it would, however, not be fit for a great space of time; for certain it is, that the resultant of the winds of a whole year would not have the same infuence on the temperature as the different components. This will appear more evident to any one who directs his attention to the differences $m t y-\theta \dot{y}$, $m t f-\theta f, m t j l-\theta j l, \& c$. He would find, not only for every place, but also for every month of the year, different influences for the same wind; the same wind producing a different cooling or heating power in different seasons, a circumstance of which account is not taken in computing the resultant.

Art. II. We will suppose that not only $\Theta$ and $\theta$, but also MT and $m t$ were obtained at a certain place from a long series of 
observations, that MT therefore could be considered as the equilibrial state of temperature at a determined season of the year at that place; then we should find that the differences OT $-\mathrm{MT}$, ot $-m t$ are to be ascribed to these circumstances :1st, that the winds had not in that space of time the same direction as usual; and 2 nd, that the distribution of temperature at the surrounding places was quite different from the usual distribution during that space of time, or shortly before. Thus it is necessary that we know the variations, not only for the place itself for which we desire to explain the temperature, but also for the surrounding places, since the variations at the first place must be explained partly from the variations at the latter. The most important causes are always to be sought in the variations (deviations); it is from those that we must derive the exhibition of the state of temperature, not from the absolute observed temperature. Even now, when we give absolute temperatures, we do in fact give deviations; namely, deviations from the arbitrary zero of temperature. Positive prognostications will always be given under the form of deviations, and best by deviations from the mean state of the atmosphere. Certainly it were to be wished that we better" understood the theoretical temperature $(\Theta)$, which must take place for certain soils and elevations above the sea, and for every latitude, in order also to be able to give the deviations from those theoretical values; but for want of that knowledge the deviations from the mean value are the main points for consideration.

Art. III. Temperature is that state which most attracts the attention of the public, in consequence of the immediate influence it has on the relations of human life; but scientifically, all states are equally important. The pressure of vapour is perhaps the most uncertain element, and of which we can give little explanation, from the manner in which it is measured; electricity is not anywhere (with exception of Brussels and Kew) sufficiently known either as to its origin or as to its quantity; it is not therefore expected that the deviations of these elements can be given. It is the winds that bring us the warm air and cold waves; they must be accurately noted as to direction and strength, but it will avail little to give their deviations from the mean direction; the winds must therefore be noted with their real directions. On the contrary, as to the barometer, the deviations again are of the greatest importance, especially as here the theoretical state is known for every latitude. Everywhere, where attention has been paid to the deviations of the barometer, which at the same time have been observed at different places or successively at the same place, 
it has led, in connexion with the observation of the wind, to practical discoveries. Who knows not the fruits of the labours of Redfield, Reid, Piddington, Thom? In later times also, the investigations of Mr. Birt on the atmospheric waves, which in November pass over England and Europe, are only deduced from the knowledge of the deviations.

As we must give so much importance to the deviations of the barometer and thermometer as to assert that they are applicable in most meteorological investigations; as we further consider how much trouble it causes for a calculator to subtract the value obtained from every observation which he uses from the mean value at that place for that day, whilst the observer can so very easily, whilst he is noting his observations, note in a column next to it the difference from the mean, we dare propose and urgently invite the observer everywhere, where the mean of each day is sufficiently known, or even where this is known with some approximation, to take this little trouble. We should then, after a lapse of five or ten years, be able to modify the mean of the temperature, and then to determine it with greater certainty. A book that contains such means for every day of the year for many places would certainly be a most useful book; and if one once possessed that, then it would be sufficient for the observers to communicate the deviations; from time to time the corrections could be published in the form of supplements.

Art. IV. England has given the example of communicating the state of the weather $*$ at a certain instant in all parts of the country, at least to Glasgow, by means of telegraph, as I saw to my surprise in the Greenock Daily Neres. My proposition made in the Changements de Température was actually in operation. Later I have also learned that that plan is likewise proposed to the British Association : thus the communication of the weather becomes more scientific than it hitherto had been. Telegraphs can, better than self-registering instruments, answer the purpose of approaching to a foretelling of the weather at all places before it exists there ; they give us the opportunity of being informed of the weather before it has passed from one place to another. We can be on our guard and arrange our occupations (our observations in the first place) accordingly; remarkable phænomena will be noticed ly different observers in corresponding manners at different places, and many other advantages will result. It is true, we shall

- This publication was principally planned and is carried into execution by the proprietors of the London Daily News. The report of the state of the weather at $9^{\mathrm{b}}$ in the moruing at numerous places is published every day in that journal.-G. B. A1RY. 
be able likewise to see from the graphic self-registering instruments the state of the weather at every instant at all places where they exist (and this is the main point of agreement of both), but only long after those circumstances are past; from the telegraphs we are acquainted with it instantaneously. It will yet be some time, we avow it, before we become sufficiently acquainted with the laws of the transit of the states of the weather, to be able to foretell with any certainty even from the known state of the weather at the neighbouring places (particularly, also, because to the class of "surrounding places" belong the places above us, and the winds and temperature reigning there); but we shall never arrive at this point except by means of exhibition of simultaneous observation. When we draw a series of theoretical deductions from a given distribution of meteorological indications (wind, heat, pressure, \&c.), and compare them with the subsequent distribution which is really found to follow as an effect of the first, we cannot fail to penetrate better the origin and influence of the winds, and moreover the variations of temperature produced by them.

Therefore it will be of importance to improve our graphic methods of representing simultaneous observations, and either by that means or by numbers to exhibit those states in a tabular form. As to the graphic method, it is to be seen in the articles of Mr. Birt, Report of the Meeting of the British Association, 1844, 1845, \&c., that there is a want of a uniform method for noting three or more variations at the same time. A good graphic method would have enabled Mr. Birt to conmunicate more in fewer pages, and to put every reader in a state to try his conclusions and to extend them.

Martins, in his annotations to the translation of Kämtz, has endeavoured to exhibit more than three variations at the same time; but that method, in our opinion, is not very clear.

Since the investigation of the great November atmospheric wave is probably to be continued, it is perhaps not inconsistent to propose another manner of exhibiting it. We can form a map of all the places where observations are made, and give to each place a sign, for example $(a),(b)$, \&c.; then the position of those signs in the other part of the drawing must express the height of the barometer at those so indicated places in the following manner. Let us draw round that map a circle, which we consider as the section of a vertical cylinder, in the plane of which those places are situated; let us further suppose that at the places $(a)(b)$ the barometers are placed with the lower surface of the mercury in the same plane of that circular section; so will the top of the highest standing barometer lie in a plane parallel to the first, and give a circular 
section of the cylinder; the distance between the two circles will be proportional to the beight of the barometer at that place. This will be true for all places; and the height of the letters or signs $(a)(b)$ noted at the respective sections in the surface of the cylinder would indicate the height of the barometer at those places. If we imagine our eye in the axis of the cylinder, and we project those supposed points $(a)(b)$ on the horizontal plane, or what is the same thing, if we apply the method of descriptive geometry to this, the greater or lower height of the barometers at $(a)(b)$ will be represented by points, $\alpha, \beta$, in circles concentric with the first, but more or less removed, whose distance from the first (the difference of the radius) will be proportional to that height. So the first circle may represent a very low barometrical height, as $730 \mathrm{mil}-$ limetres, and each millimetre that the barometer in $(a)$ or $(b)$ is higher may be represented by one or two millimetres' distance of the circle $(\alpha)$ or $(\beta)$ from the first. But we can go a step further; we can divide those circles from the common centre point into a number of sectors, thirty sectors I suppose: in one sector the letters may signify the height of the barometer at the 20th of October, in another at the 21 st, and so on; every sector may be applied to one day. So we shall have the barometrical range at every one place, and the different states at the different places simultaneously, equally well and clearly represented, while the map within the circle indicates the distribution with respect to the surface of the earth. If, by chance, the points $(a)$ in the different sectors lie in a circle, it indicates that the barometer at $a$ has not varied during the month; if they lie in an ellipse, then there have been two highest and two lowest states; we see immediately those heights and the dates. So, as to the simultaneous comparison of the barometer heights, the eye catches immediately the letters that are higher or lower, and we see on the map in the middle the line of places where the barometer was at the highest or the lowest. If there actually is a wave, then it is clearly exhibited thus to the eye; if the eye has difficulty in discerning the wave, then probably there is no wave, or perhaps that wave must have been marked out by the foregoing or following days.

It is even possible to go a step further, and, for example, to represent at the same time the thermometer state by the distances at which we set the letters $(a),(b)$ (the signs of the places) from the radii which divide the circle; the more on the right, for example, the higher the state of the thermometer. It is evident, however, that the more variations we exhibit, the more is lost in simplicity. We could have 
represented also latitude, longitude, time, barometer, thermometer. How much soever we improve the graphic representation, we must however always, where there is not merely a view required but an accurate calculation, have recourse to a tabular exhibition. To promote this, the Utrecht Provincial Society for Arts and Sciences has issued the following prize question:-

Since the usual indications of thermometer, barometer, and anemometer throughout the year, that is, the periodical functions by which those indications are expressed, are now known for a great number of places, at least with approximation, and thus a sufficient basis is laid for the investigation of nonperiodical changes; the Society wishes-

After having calculated the mean indications of thermometer, barometer and anemometer, over as great a number of places as possible in Europe and Asiatic Russia for periods of five days for two successive years,-

1. The deviations of thermometer and barometer from their above-described usual state in each of those periods, should be united in tables;

2. The manner of transit of those deviations in time and space should be investigated; and

3. Those deviations should be compared and brought in connexion with the winds that prevailed during each of the said periods, and with the deviation from their usual direction which they exhibited.

The importance of this prize proposition in connexion with the various researches which are required for its investigation, has induced the author of this question to augment the offered prize with one hundred and fifty guilders. It is wished that the answer be received before October 1, 1851, by M. C. von Marle, Secretary of the Utrecht Provincial Society for Arts and Sciences. The name of the author, as usual, in a separate letter.

Utrecht.

Postscript.-I have not mentioned in my memoir that the observations instituted by the Royal Society have lately been computed, and that the means of each month are in fact subtracted from the mean of the months of the same name. I had not seen the last part of the Philosophical Transactions in which these computations are placed. 